\title{
Efficiency Assessment of a Signalized Roundabout and a Traffic Intersection in Baghdad City
}

\author{
Hajir Hussein Mohammed \\ Civil Engineering Department \\ Baghdad University \\ Baghdad, Iraq \\ h.arkwazee1901m@coeng.uobaghdad.edu.iq
}

\author{
Mohammed Qadir Ismail \\ Civil Engineering Department \\ Baghdad University \\ Baghdad, Iraq \\ drmohammedismael@coeng.uobaghdad.edu.iq
}

\begin{abstract}
In Baghdad city, Iraq, the traffic volumes have rapidly grown during the last 15 years. Road networks need to reevaluate and decide if they are operating properly or not regarding the increase in the number of vehicles. Al-Jadriyah intersection (a four-leg signalized intersection) and Kamal Junblat Square (a multi-lane roundabout), which are two important intersections in Baghdad city with high traffic volumes, were selected to be reevaluated by the SIDRA package in this research. Traffic volume and vehicle movement data were abstracted from videotapes by the Smart Traffic Analyzer (STA) Software. The performance measures include delay and LOS. The analysis results by SIDRA Intersection 8.0.1 show that the performance of the roundabout is better than the signalized intersection but experiences high delay, and low LOS. Therefore, alternatives are proposed to improve the performance for current and future traffic volumes with low-medium delays.
\end{abstract}

Keywords-signalized intersection; multi-lane roundabout; delay; LOS

\section{INTRODUCTION}

Road traffic congestion comprises several complex procedures and incorporates numerous components cooperating simultaneously. In such a condition, a simulation modeler can be a very effective tool as it provides evaluations for various traffic conditions [1]. The increment in the demand for private transportation increases traffic congestion during peak hours [2, $3]$. The streets are a key component and the vital arteries of a city, as well as an important timekeeper compass for the movement of the population in the city. Streets intersect with each other and intersections can be either controlled or uncontrolled. One of the best methods to facilitate the traffic at uncontrolled intersections is roundabouts. Frequently, the presence of a roundabout is inevitable because of its advantages such as reduced delays, improved traffic flow, safety, fewer conflicts, and economy. When rising rates of congestion and accidents are observed, there is a need to study this problem to find a solution. There is no doubt that the traffic problems whether congestion-related or accidents comprise crucial problem for most countries. However, the phenomenon of traffic congestion in the streets [4], especially in the streets which are not controlled by traffic control devices, has been exacerbated dramatically in recent years, especially in
Baghdad. The problem of increasing traffic volume is that the absorptive capacity of the roads is not able to accommodate the traffic flow at peak hours resulting in traffic congestion and accidents. Human factors account for $67 \%$ of the accidents, while road conditions account for $29 \%$, and vehicle defects for $4 \%$ [5]. Many remedies have been proposed to prevent or reduce the accident rates, including proper driver education and sign boards and traffic signals wherever they are needed. Every highway should be made to have three lanes in each direction (two lanes would suffice for roads) and the roads should be properly maintained [6]. Variable Speed Limits (VSLs) are used to improve highway performance in terms of comfort and safety [7].

The operational performance evaluation will be conducted using the intelligent software SIDRA Intersection 5 which is a micro-analytical traffic evaluation tool that employs lane-bylane and vehicle drive cycle models [8]. Its function is to compare different treatments of separate intersections as well as networks of intersections involving signalized and unsignalized intersection roundabouts. Authors in [9] studied the conversion option of 3-leg and 4-leg roundabouts to signalized 3-leg and 4-leg intersections. The performance of real exiting roundabouts in Jeddah and Al-Madinah cities was evaluated. In terms of performance, the signalized intersection is the recommended option for the 3-leg roundabouts when the degree of saturation is over $80 \%$ and there is high left-turning volume. In [10], the authors studied the capacity and performance of the roundabouts In Nigeria, Makurdi, Wurukum using ARCADY and SIDRA Intersection. They suggested the use of fly-over bridges, the alteration of geometrical features, and the signalization of the roundabouts with road signs and proper pavement markings. Authors in [11] evaluated the performance of nested signalized roundabouts located in Niğde, Turkey, and compared the roundabout intersection solutions with the HCS6 method using the SIDRA Intersection software. The analysis showed that with the application of a modern roundabout, higher performance was observed. The average delay decreased by $72.8 \%$, while the capacity increased by $67.8 \%$. Their conclusion was that the use of roundabout control instead of a nested signal system might increase the performance of traffic flow. In [12], the authors 
used SIDRA Intersection to compare the operational performance evaluation of conventional signalized and nonsignalized roundabouts and the potential replacement of conventional roundabouts with turbo ones. The delay time for the conventional signalized and non-signalized roundabouts was $407.2 \mathrm{~s}$ and $337.6 \mathrm{~s}$ respectively and LOS was F with forced or breakdown flows for both roundabouts. The authors concluded that the implementation of turbo roundabouts might reduce the risk of fatalities by $80 \%$ and increase the capacity by forcing the drivers to use inner lanes.

Authors in [13] used SIDRA to evaluate LOS and delays of the Al-Turkman Roundabout in Baghdad to improve its performance by proposing planning procedures to address the traffic jam and congestion problems in this area. In [14], the authors studied the performance of two signalized intersections in Bangi, Malaysia using the SIDRA software. The conclusion was that signalized intersection 2 performed better than the signalized intersection 1. Authors in [15] examined two signalized intersections using Sidra Intersection 5.1 based on the Australian, and American HCM methods and proposed new cycle times to improve their performance. The capacity values of Kule and Nalçaci-Sille signalized intersections according to the Australian method were higher than those obtained with the American method by about $7 \%$. Similarly, the delay and the degree of saturation values according to the Australian method were lower by about $11 \%$ and $8 \%$ respectively. The Australian and the American methods proposed an optimum cycle time of $125 \mathrm{~s}$ and $145 \mathrm{~s}$ for Kule Intersection. Similarly, $70 \mathrm{~s}$ and $85 \mathrm{~s}$ were proposed respectively for the Nalçac1-Sille intersection. Therefore, the Australian method was considered better than the American method in terms of proposed cycle times because the traffic is affected negatively by long cycle times.

Authors in [16] studied the performance of three 4-leg signalized intersections and four roundabouts in Karbala city, Iraq using SIDRA Intersection and proposed alternatives for performance improvement. All the outputs were categorized by medium to high total delays, thus the level of service for most of the intersections was (F). Some alternatives were suggested: the performance of the intersection improved by about $50 \%$ with pavement remarking and lane designation and the MOE of the intersections improved by about $66 \%$ by pavement widening. In [17], the authors studied an optimization method of the factors that affect the signalized intersection operation. Three signalized intersections located in Al-Mansur, Baghdad were selected. The calibrated analysis results showed that after cycle time improvement application, the delay and queue length decreased.

Authors in [18] studied the operational performance of one highway, three intersections, and seventeen urban roads in AlKadhimiya, Baghdad, with the HCS2000 software and proposed performance improvement alternatives. The LOS of all intersections in existed conditions was (F). Increasing the number of lanes and selecting the best cycle time was suggested as the best alternatives for all signalized intersections and arterial roads. The LOS improved to (C), and in addition to the overpass alternative, the LOS was upgraded to (B) for signalized intersections. At the same time, the LOS of arterial roads improved and varied between $(\mathrm{C})$ and $(\mathrm{E})$. Total delay was sufficiently decreased, and the operational performance improved for all intersections.

\section{METHODOLOGY}

Kamal Junblat Square (a 4-leg roundabout intersection) and Al-Jadriyah Intersection (a 4-leg signalized intersection) located in Baghdad city, Iraq (Figures 1-2) were selected to have their performance evaluated.

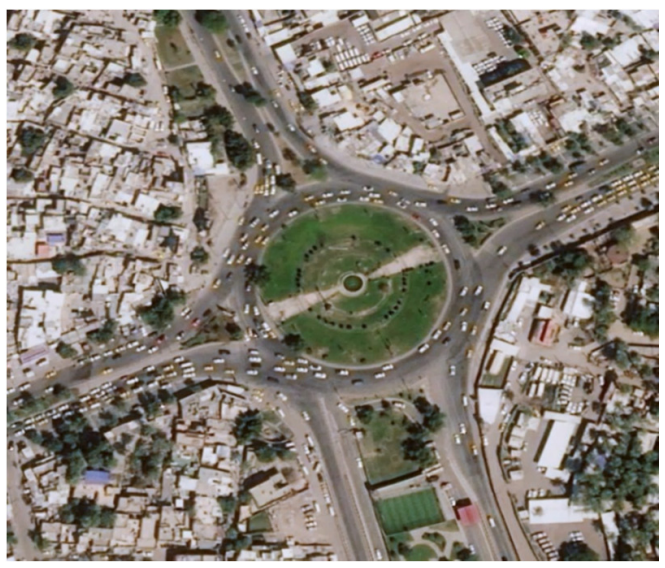

Fig. 1. Kamal Junblat quare (Google Earth, (C) Maxar Technologies).

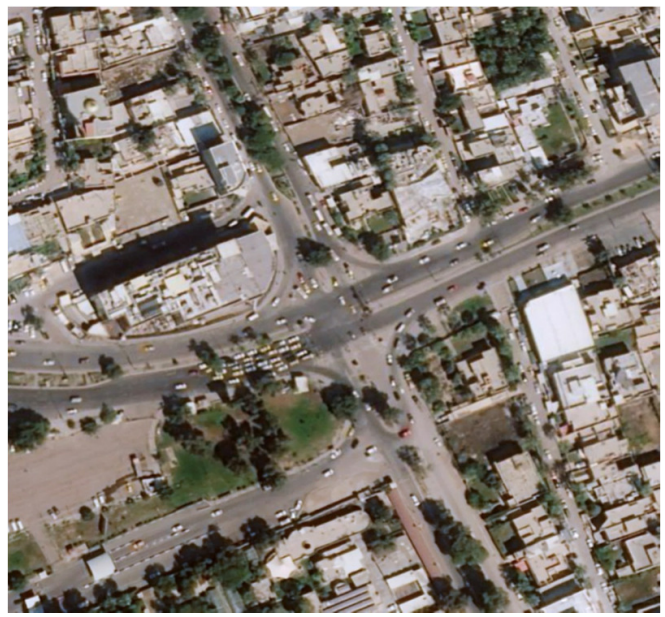

Fig. 2. Al-Jadriyah intersection (Google Earth, (C) Maxar Technologies).

The traffic data were collected for 10 regular working weekdays (from 17/01/2021 to 21/01/2021, and 07/02/2021 to $11 / 02 / 2021$ ) with no holidays, no accidents, or unnatural security activities. The weather conditions on each video recording were normal without rain and the visual conditions were good. Two peak periods were acknowledged from the video observation. At least two hours are recommended to straddle the peak hour time since the traffic on various approaches usually vary, and it is necessary to ensure that the peak hour of each approach is included [19]. The morning period consists of 3 hours (from 7:00 AM to 10:00 AM) and the evening period consists of 2 hours (from 1:00 PM to 3:00 $\mathrm{PM})$. The traffic data were extracted from videotapes with the use of the Smart Traffic Analyzer (STA) software as presented in Figure 3. 


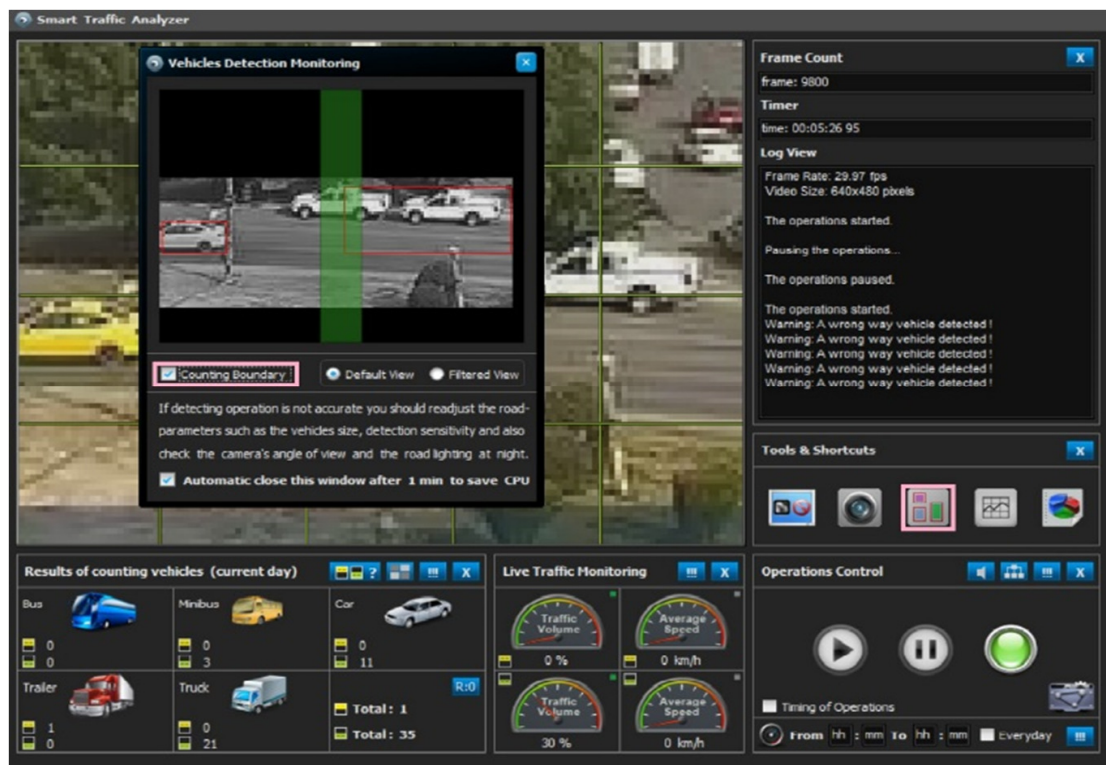

Fig. 3. Collecting traffic volume and vehicle classification with the STA program.

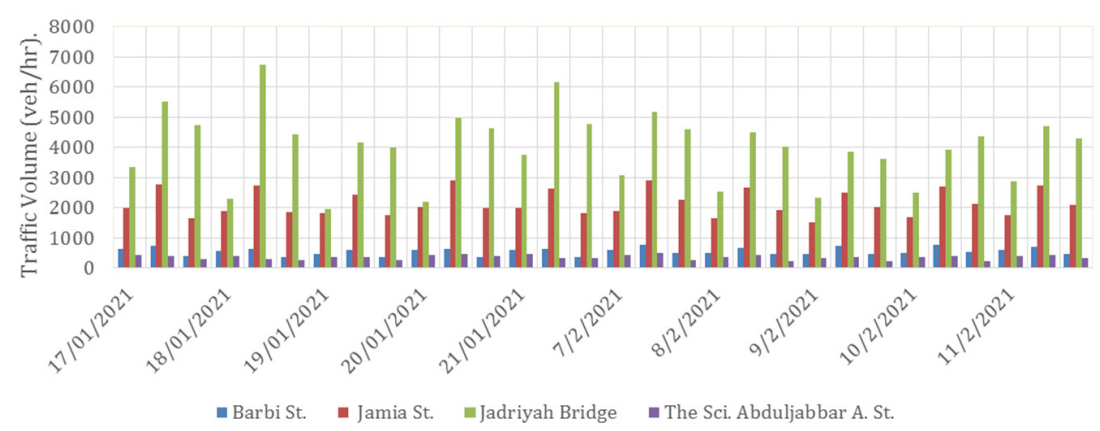

Fig. 4. Traffic volume of the morning period (Al-Jadriyah intersection).

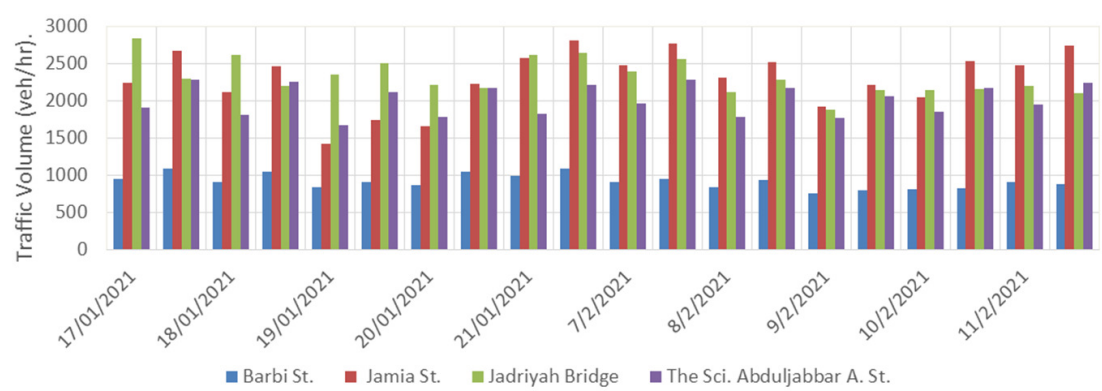

Fig. 5. Traffic volume of the evening period (Al-Jadriyah intersection).

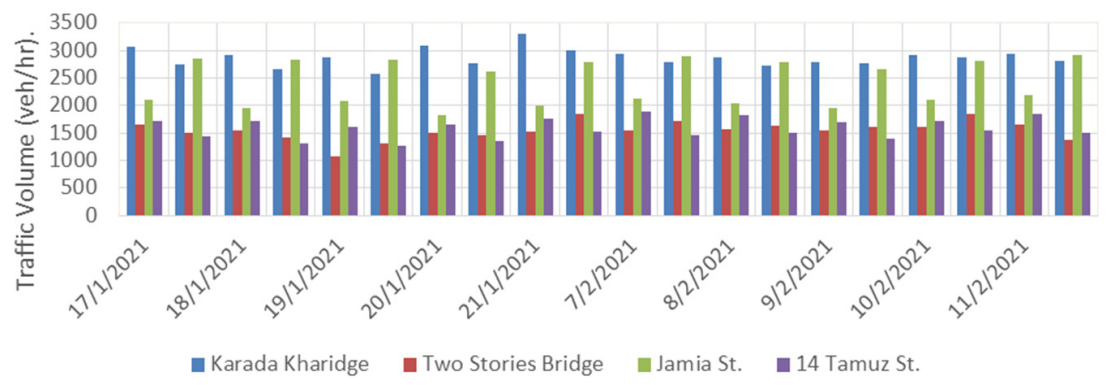

Fig. 6. Traffic volume of the morning period (Kamal Junblat Square). 


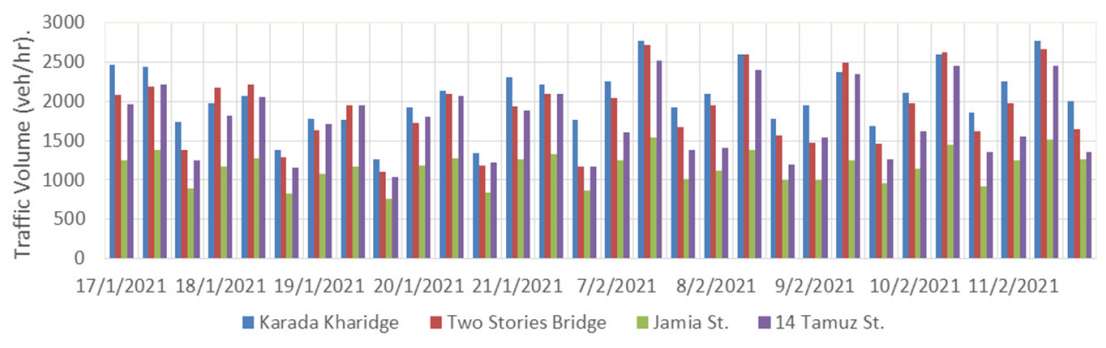

Fig. 7. Traffic volume of the evening period (Kamal Junblat Square).

Vehicle classifications and vehicle movements for the signalized intersection counted by the STA software are shown in Figures 8-11.

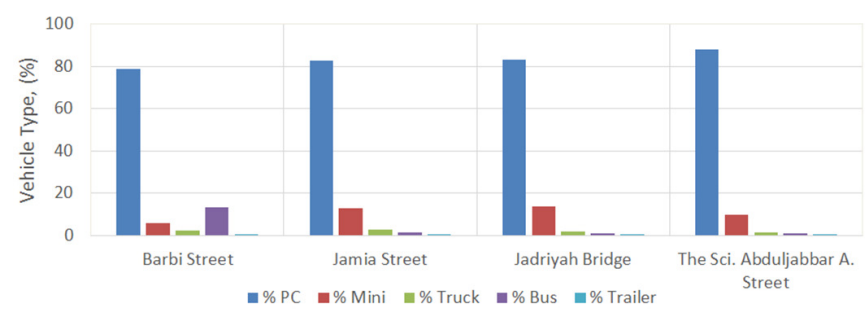

Fig. 8. Vehicle classification percentage for Al-Jadriyah intersection.

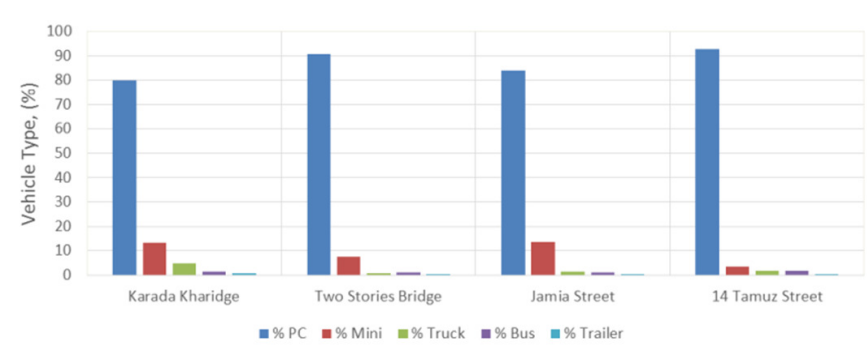

Fig. 9. Vehicle classification percentage for Kamal Junblat Square.

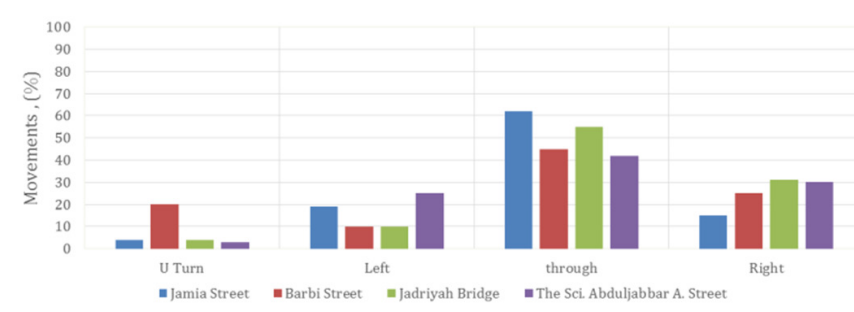

Fig. 10. Vehicle movement percentage for Al-Jadriyah intersection.

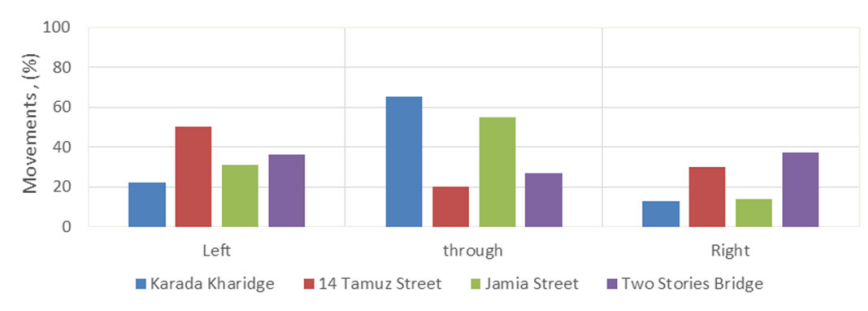

Fig. 11. Vehicle movement percentage for Kamal Junblat Square.

\section{RESULTS}

To discuss the current conditions of traffic operation and the geometry on traffic flow performance, the required actual movement was acquired by applying SIDRA Intersection 8.0.1. The abstracted and collected data were fed to the program for each intersection separately. Many runs were implemented to exclude bias data. Table I presents the delay and the LOS of the roundabout. The delay of 14 Tamuz is $50.1 \mathrm{~s} / \mathrm{veh}$ and of Tow Stories Bridge is $120.6 \mathrm{~s} / \mathrm{veh}$ due to the high circulating volume (the biggest portion of vehicles from Karadad Kharide and Jamia St.) in the entrance causing high conflict points leading to congestions with high delay. Although the traffic volumes of Karadad Kharide and Jamia St. are high, the delays are $40.5 \mathrm{~s} / \mathrm{veh}$, and $35.4 \mathrm{~s} / \mathrm{veh}$ respectively due to their geometry and low-medium circulating volume in their entrance (the result of the congestion in front of the other approaches). Delay is an important parameter to evaluate the LOS of a roundabout thus the LOS is D, E, D, and F for Karada Kharidge, 14 Tamuz St., Jamia St., and Tow Stories Bridge respectively. The control delay and LOS for individual lanes are illustrated in Figures 12, and 13 .

All the output results are categorized by medium to high total delays. The total delay is $127.84 \mathrm{veh}-\mathrm{h} / \mathrm{h}$, the average geometric delay is $2.7 \mathrm{~s} / \mathrm{veh}$, and the average control delay of the roundabout is $57.2 \mathrm{~s} / \mathrm{veh}$, thus the level of service for the roundabout is $\mathrm{E}$ according to the LOS categories of the software that are based on the SIDRA method. The LOS of four/five approach multi-lane roundabout suffering medium/high volumes and delays is ranging from $\mathrm{E}$ to $\mathrm{F}$ according to $[10,13,22]$.

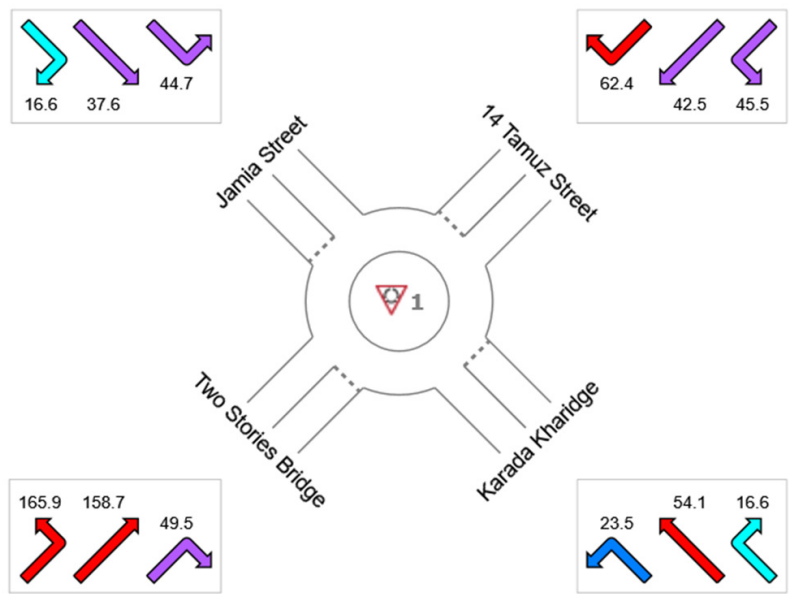

Fig. 12. Resulting average (control) delay of the individual lanes of Kamal Junblat Square. 


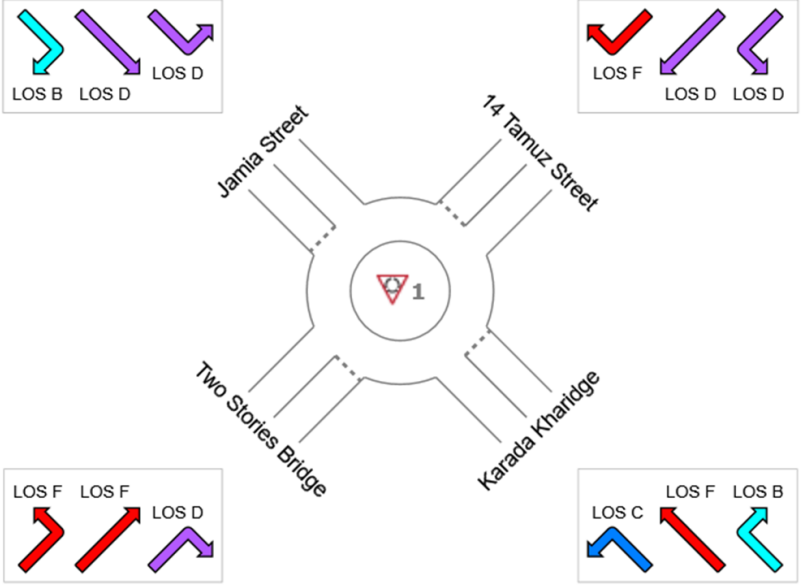

Fig. 13. Resulting LOS of the individual lanes of Kamal Junblat Square

TABLE I. AVERAGE (CONTROL) DELAY AND LOS OF THE INDIVIDUAL LANES OF KAMAL JUNBLAT SQUARE

\begin{tabular}{|c|c|c|c|c|c|}
\hline & \multicolumn{4}{|c|}{ Approaches } & \multirow{2}{*}{} \\
\cline { 2 - 5 } & $\begin{array}{c}\text { Karada } \\
\text { Kharidge }\end{array}$ & $\begin{array}{c}\text { 14 Tamuz } \\
\text { St. }\end{array}$ & $\begin{array}{c}\text { Jamia } \\
\text { St. }\end{array}$ & $\begin{array}{c}\text { Two Stories } \\
\text { Bridge }\end{array}$ & Intersection \\
\hline $\begin{array}{c}\text { Delay } \\
\text { (control) }\end{array}$ & 40.5 & 50.1 & 35.4 & 120.6 & 57.2 \\
\hline LOS & D & E & D & F & E \\
\hline
\end{tabular}

Regarding the performance of the Al-Jadriyah intersection, the maximum cycle time according to [23] (120s) was inputted to SIDRA Intersection. The output phase sequence of each approach of the intersection is shown in Table II. Jamia St. phase time is considered as the reference phase. The reference phase merely indicates the phase that is coordinated in a SIDRA network model. Although of no significance for individual sites, one phase needs to be selected [24].

TABLE II. OUTPUT PHASE SEQUENCE FOR EACH APPROACH OF ALJADRIY AH INTERSECTION

\begin{tabular}{|c|c|c|c|c|c|}
\hline & \multicolumn{4}{|c|}{ Approaches } & \multirow[b]{2}{*}{ Remark } \\
\hline & $\begin{array}{c}\text { Jamia } \\
\text { St. }\end{array}$ & $\begin{array}{c}\text { Barbi } \\
\text { St. }\end{array}$ & $\begin{array}{c}\text { Jadriyah } \\
\text { Bridge }\end{array}$ & $\begin{array}{c}\text { Sci Abduljabbar } \\
\text { A. St. }\end{array}$ & \\
\hline Phase A & $\mathrm{R}$ & $\mathrm{R}$ & $\mathrm{G}$ & $\mathrm{R}$ & - \\
\hline Phase B & $\mathrm{R}$ & $\mathrm{G}$ & $\mathrm{R}$ & $\mathrm{R}$ & - \\
\hline Phase C & $\mathrm{G}$ & $\mathrm{R}$ & $\mathrm{R}$ & $\mathrm{R}$ & REF \\
\hline Phase D & $\mathrm{R}$ & $\mathrm{R}$ & $\mathrm{R}$ & $\mathrm{G}$ & - \\
\hline
\end{tabular}

The control delay is $285.2 \mathrm{~s}, 140.1 \mathrm{~s}, 197.9 \mathrm{~s}$, and $190.5 \mathrm{~s}$ for Jamia St., Barbi St., Jadriyah Bridge, and Sci Abduljabbar A. St. respectively as shown in Table III. The average control delay of the signalized intersection is $228.5 \mathrm{~s}$, the total control delay is $542.96 \mathrm{veh}-\mathrm{h} / \mathrm{h}$, and the average geometric delay is 2.6s. As previously mentioned, LOS is determined based on the delay for a signalized intersection, thus the LOS of all the approaches of Al-Jadriyah intersection and the intersection itself is F according to the HCM2010 method due to the high delay as the result of high traffic volume and the inadequate geometric dimensions of the intersection to discharge this high volume functionally $[8,25]$. Control delay and LOS for the individual lanes are illustrated in Figures 14 and 15.
TABLE I. CONTROL DELAY AND LOS OF KAMAL JUNBLAT SQUARE

\begin{tabular}{|c|c|c|c|c|c|}
\hline & \multicolumn{4}{|c|}{ Approaches } & \multirow[b]{2}{*}{ Intersection } \\
\hline & $\begin{array}{c}\text { Karada } \\
\text { Kharidge }\end{array}$ & $\begin{array}{c}14 \\
\text { Tamuz } \\
\text { St. }\end{array}$ & $\begin{array}{c}\text { Jamia } \\
\text { St. }\end{array}$ & $\begin{array}{c}\text { Two } \\
\text { Stories } \\
\text { Bridge }\end{array}$ & \\
\hline $\begin{array}{c}\text { Delay } \\
\text { (control) (s.) }\end{array}$ & 40.5 & 50.1 & 35.4 & 120.6 & 57.2 \\
\hline LOS & $\mathrm{D}$ & $\mathrm{E}$ & $\mathrm{D}$ & $\mathrm{F}$ & $\mathrm{E}$ \\
\hline $\begin{array}{c}\text { Control Delay } \\
\text { (s) (SIDRA } \\
\text { standard) } \\
\end{array}$ & $\leq 10$ & $>10-20$ & $\begin{array}{c}>20- \\
35\end{array}$ & $>35-55$ & $>50-70$ \\
\hline $\begin{array}{c}\text { LOS (SIDRA } \\
\text { standard) }\end{array}$ & A & B & $\mathrm{C}$ & $\mathrm{D}$ & $\mathrm{E}$ \\
\hline
\end{tabular}

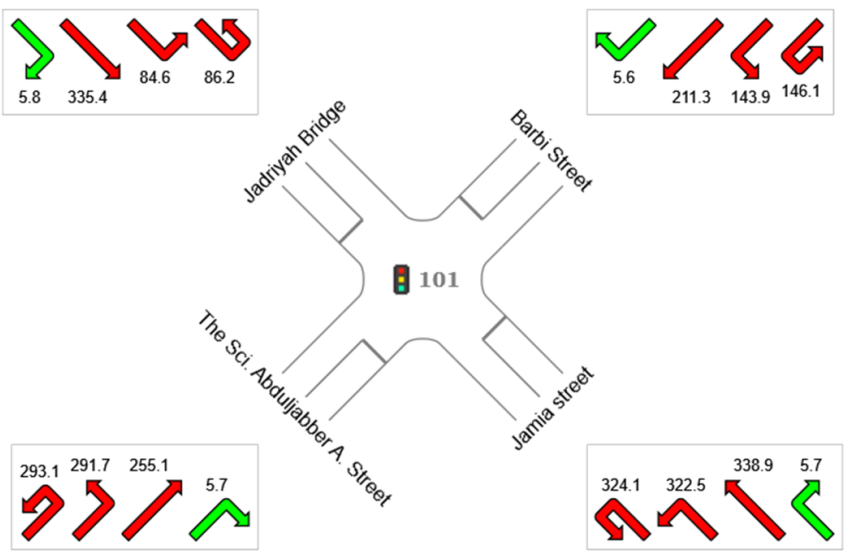

Fig. 14. Resulting average (control) delay of the individual lanes of AlJadriyah Intersection.

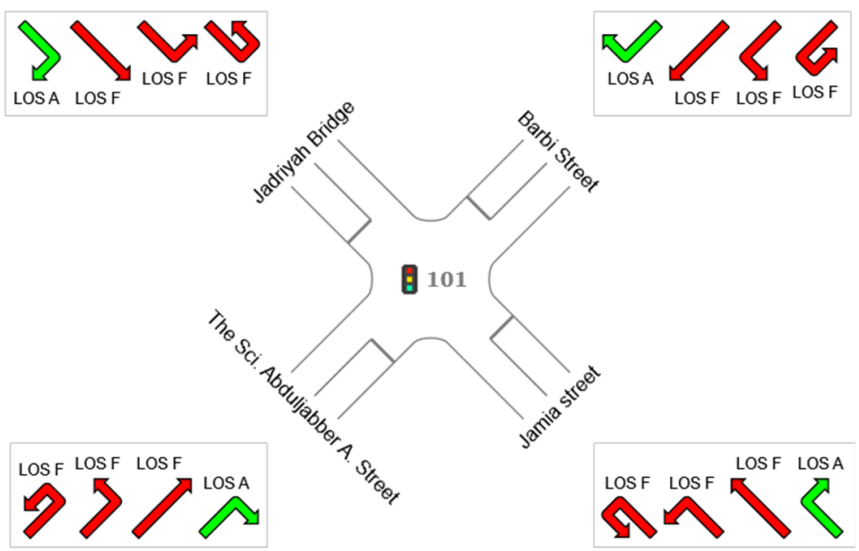

Fig. 15. Resulting LOS of the individual lanes of Al-Jadriyah Intersection.

\section{Alternatives SUGGESTED TO IMPROVE THE PERFORMANCE OF THE INTERSECTIONS}

An additional circulating lane improved the roundabout by about $18 \%$. The control delay and LOS were about $57.2 \mathrm{~s}$ and $\mathrm{E}$ and were improved to $46.8 \mathrm{~s}$ and $\mathrm{D}$ respectively as shown in Table IV. Fly-over connection between 14 Tamuz Street and Two Stories Bridge approaches was the second suggested improvement and enhanced the roundabout by about $72 \%$, improving control delay and LOS to $15.9 \mathrm{~s}$ and $\mathrm{B}$ respectively as illustrated in Table V. A third proposal was the addition of another lane for each of the 14 Tamuz Street and Two Stories 
Bridge approaches. LOS and control delay of the roundabout were enhanced to $\mathrm{C}$ and $27.8 \mathrm{~s}$ respectively as presented in Table VI, therefore the improvement was about $51 \%$.

TABLE II. AVERAGE (CONTROL) DELAY AND LOS OF KAMAL JUNBLAT SQUARE (ADDITIONAL CIRCULATING LANE PROPOSAL)

\begin{tabular}{|c|c|c|c|c|c|}
\hline & \multicolumn{4}{|c|}{ Approaches } & \multirow{2}{*}{ Intersection } \\
\cline { 2 - 6 } & Southeast & Northeast & Northwest & Southwest & \\
\hline Delay (control) (s) & 51.8 & 48.5 & 8.3 & 92.3 & 46.8 \\
\hline LOS & $\mathrm{E}$ & $\mathrm{D}$ & $\mathrm{A}$ & $\mathrm{F}$ & $\mathrm{D}$ \\
\hline
\end{tabular}

TABLE III. AVERAGE (CONTROL) DELAY AND LOS OF KAMAL JUNBLAT SQUARE (FLY-OVER PROPOSAL)

\begin{tabular}{|c|c|c|c|c|c|}
\hline & \multicolumn{3}{|c|}{ Approaches } & \multirow{2}{*}{ Intersection } \\
\cline { 2 - 6 } & Southeast & Northeast & Northwest & Southwest & \\
\hline Delay (control) (s) & 15.1 & 31.4 & 6.3 & 22.4 & 15.9 \\
\hline LOS & B & C & A & C & B \\
\hline
\end{tabular}

TABLE IV. AVERAGE (CONTROL) DELAY AND LOS OF KAMAL JUNBLAT SQUARE (ADDITIONAL LANE FOR 14 TAMUZ AND TWO STORIES BRIDGE PROPOSAL)

\begin{tabular}{|c|c|c|c|c|c|}
\hline & \multicolumn{3}{|c|}{ Approaches } & \multirow{2}{*}{ Intersection } \\
\cline { 2 - 6 } & Southeast & Northeast & Northwest & Southwest & \\
\hline Delay (control) (s) & 45.0 & 22.5 & 12.8 & 26.7 & 27.8 \\
\hline LOS & D & C & B & C & C \\
\hline
\end{tabular}

Regarding the Al-Jadriyah Intersection, selecting the optimum cycle time (50s) with the fly over proposal was suggested as the first improvement alternative while the second was the use of the optimum cycle time (70s) with the addition of a lane for each approach of theintersection. The intersection was enhanced by about $91 \%$ with the first proposal and by $67 \%$ with the second proposal. Control delay time and LOS improved to $20.2 \mathrm{~s}$ and $\mathrm{C}$ and $74.7 \mathrm{~s}$ and $\mathrm{D}$ respectively with the first and second improvement proposal as shown in Tables VII and VIII.

TABLE V. AVERAGE (CONTROL) DELAY AND LOS OF AL-JADRIYAH INTERSECTION (FIRST PROPOSAL)

\begin{tabular}{|c|c|c|c|c|c|}
\hline & \multicolumn{4}{|c|}{ Approaches } & \multirow{2}{*}{ Intersection } \\
\cline { 2 - 6 } & Southeast & Northeast & Northwest & Southwest & \\
\hline Delay (control) (s) & 23.3 & 26.9 & 14.6 & 20.7 & 20.2 \\
\hline LOS & C & C & B & C & C \\
\hline
\end{tabular}

TABLE VI. AVERAGE (CONTROL) DELAY AND LOS OF AL-JADRIYAH INTERSECTION (SECOND PROPOSAL)

\begin{tabular}{|c|c|c|c|c|c|}
\hline & \multicolumn{3}{|c|}{ Approaches } & \multirow{2}{*}{ Intersection } \\
\cline { 2 - 6 } & Southeast & Northeast & Northwest & Southwest & \\
\hline Delay (control) (s) & 94.3 & 34.9 & 70.1 & 31.1 & 74.7 \\
\hline LOS & F & C & E & C & E \\
\hline
\end{tabular}

\section{CONCLUSION}

From field/video observations and simulation, the performances of the Kamal Junblat Square roundabout and the signalized Al-Jadriyah Intersection with high traffic volume were compared. The roundabout shows better performance than the signalized intersection. The LOS and delay time of the roundabout were $\mathrm{E}$ and $57.2 \mathrm{~s}$ and of the Al-Jadriyah Intersection were $\mathrm{F}$ and $228.5 \mathrm{~s}$. The signalized intersection suffers from a long cycle length (120s) that causes high delay time values. The increase of circulating volume causes a decrease in entry capacity, while the increase in the geometric feature dimensions (width of entry, entry radius, and inscribed circle diameter) increases the entry capacity, with one exception.

In the roundabout, domain approaches (Jamia St., and Karada Kharidge) cause high circulating volume in the subdomain (14- Tamuz, and Two-Stories Bridge) entries, thus the LOS of these approaches $(\mathrm{F})$ is worse than the domain approaches (D). Domain approaches in the roundabout operate properly in medium/high traffic situations, while the subdomain approaches suffer from high delays due to the accommodation of high circulating volumes in their entries.

The addition of a circulating lane and of a lane to the subdomain approaches improves the operation performance of the roundabout by an average of $18 \%$ and $51 \%$ respectively. The addition of one lane for each approach of the intersection enhances the performance of the signalized intersection by $67 \%$ in average.

A fly-over connection between sub-domain approaches enhances the roundabout performance by about $72 \%$ and a flyover connection between Jamia St. and Jadriyah Bridge with optimum cycle time of $50 \mathrm{~s}$ improves the operational performance of the Al-Jadriyah Intersection by about $91 \%$. Thus, the fly-over is considered the best improvement alternative proposal.

\section{REFERENCES}

[1] G. Papageorgiou, P. Damianou, A. Pitsilides, A. Thrasos, and P. Ioannou, "A Microscopic Traffic Simulation Model for Transportation Planning in Cyprus," in International Conference on Intelligent Systems And Computing: Theory And Applications, Ayia Napa, Cyprus, Jul. 2006, pp. 157-166.

[2] A. J. Essa, A. Ismail, A. E. Jehad, A. A. Adheem Hussein, A. H. Khalaf, and H. A. M. Yahia, "Development of Roundabout Delay Models Using Traffic Simulation Programs: A Case Study at Al-Mansour City, Iraq," Jurnal Kejuruteraan, vol. 29, no. 2, pp. 97-103, Dec. 2017, https://doi.org/10.17576/jkukm-2017-29(2)-05.

[3] H. A. M. Yahia, S. Safinia, N. K. Al Musharfi, and S. S. I. A. Ali, "Car Driver Attitude towards Road Safety Measures," Jurnal Kejuruteraan, vol. 29 , no. 1 , pp. 57-61, Oct. 2017 , https://doi.org/10.17576/jkukm2017-29(1)-08.

[4] M. M. Islam and A. Y. S. Al Hadhrami, "Increased motorization and road traffic accidents in Oman," Journal of Emerging Trends in Economics and Management Sciences, vol. 3, no. 6, pp. 907-914, Dec. 2012, https://doi.org/10.10520/EJC130254.

[5] M. Touahmia, "Identification of Risk Factors Influencing Road Traffic Accidents," Engineering, Technology \& Applied Science Research, vol. 8, no. 1, pp. 2417-2421, Feb. 2018, https://doi.org/10.48084/etasr.1615.

[6] A. Detho, S. R. Samo, K. C. Mukwana, I. A. Memon, and U. A. Rajput, "Proposed Remedies to Prevent Road Traffic Accidents (RTAs) on Highways in Pakistan," Engineering, Technology \& Applied Science Research, vol. 8, no. 5, pp. 3366-3368, Oct. 2018, https://doi.org/ 10.48084/etasr.2128.

[7] M. Z. Hasanpour, M. R. Ahadi, A. S. Moghadam, and G. A. Behzadi, "Variable Speed Limits: Strategies to Improve Safety and Traffic Parameters for a Bottleneck," Engineering, Technology \& Applied 
Science Research, vol. 7, no. 2, pp. 1535-1539, Apr. 2017, https://doi.org/10.48084/etasr.831.

[8] H. I. M. Irtema, A. Ismail, S. I. Albrka, M. A. Ladin, and H. A. M. Yahia, "Evaluating the Performance of Traffic Flow in Four Intersections and Two Roundabouts in Petaling Jaya and Kuala Lumpur Using Sidra 4.0 Software," Jurnal Teknologi, vol. 72, no. 4, pp. 1-5, Jan. 2015, https://doi.org/10.11113/jt.v72.3906.

[9] M. Owais, O. Abulwafa, and Y. A. Abbas, "When to Decide to Convert a Roundabout to a Signalized Intersection: Simulation Approach for Case Studies in Jeddah and Al-Madinah," Arabian Journal for Science and Engineering, vol. 45, no. 10, pp. 7897-7914, Oct. 2020, https://doi.org/10.1007/s13369-020-04479-6.

[10] P. T. Adeke, A. Etika, and A. A. Atoo, "Capacity and Performance Assessment of Wurukum Roundabout in Makurdi Metropolis: A Comparative Study using ARCADY and SIDRA INTERSECTION Software," Arid Zone Journal of Engineering, Technology and Environment, vol. 16, no. 2, pp. 309-320, Jun. 2020.

[11] H. G. Demir and Y. K. Demir, "A Comparison of Traffic Flow Performance of Roundabouts and Signalized Intersections: A Case Study in Nigde," The Open Transportation Journal, vol. 14, no. 1, pp. 120 132, Jul. 2020, https://doi.org/10.2174/1874447802014010120.

[12] L.-S. Tey, M. S. Salim, S. M. R. Shah, and P. Ranjitkar, "Safety and Operational Performance of Roundabouts," International Journal of Engineering and Advanced Technology, vol. 8, no. 6S3, pp. 198-203, Nov. 2019, https://doi.org/10.35940/ijeat.F1032.0986S319.

[13] G. M. Aboud, A. M. Abdulwahab, Q. S. Banyhussan, and H. A. Zubaidi, "A Case Study on Roundabout under Congestion: Proposal to Improve Current Traffic Operation," Civil Engineering Journal, vol. 5, no. 9, pp. 2029-2040, Sep. 2019, https://doi.org/10.28991/cej-2019-03091391.

[14] J. Mohammed and A. A. M. D. O. Ali, "Traffic Flow Analysis for Intersection Using Computer Simulation Aasidra Software: A Case Study in Bangi Malaysia," Tikrit Journal of Engineering Sciences, vol. 20, no. 4, pp. 10-25, May 2014.

[15] M. M. Akmaz and O. N. Celik, "Examination of Signalized Intersections According to Australian and HCM (Highway Capacity Manual) Methods Using Sidra Intersection Software," Journal of Civil Engineering and Architecture, vol. 10, no. 2, pp. 246-259, Feb. 2016, https://doi.org/10.17265/1934-7359/2016.02.013.

[16] G. Sofia, A. Al-Haddad, and I. S. Al-Haydari, "Improvement of traffic performance at intersections in Karbala city," MATEC Web of Conferences, vol. 162, 2018, Art. no. 01032, https://doi.org/10.1051/ matecconf/201816201032.

[17] M. K. Al-Obaidi, "Enhancement of the Traffic Operation Performance of Al-Mansour Signalized T-Intersection in Baghdad City," Association of Arab Universities Journal of Engineering Sciences, vol. 25, no. 5, pp. 190-210, 2018.

[18] M. Q. Ismael and A. J. Mohammed, "Improvement of Traffic Movement for Roads Network in Al-Kadhimiya City Center," Journal of Engineering, vol. 22, no. 9, pp. 182-205, Sep. 2016.

[19] L. J. Pignataro and E. J. Cantilli, Traffic Engineering: Theory and Practice. Hoboken, NJ, USA: Prentice-Hall, 1973.

[20] National Cooperative Highway Research Program, Roundabouts: An Informational Guide, Second Edition., no. Report 672. Washington, DC, USA: Transportation Research Board, 2010.

[21] Federal Highway Administration, Roundabouts : an informational guide, no. FHWA-RD-00-067; Washington, DC, USA: US Department of Transportation, 2000.

[22] M. R. Haque, M. A. Rahman, M. B. Hossain, and M. Roknuzzaman, "Capacity Evaluation of Roundabout Intersections in Khulna Metropolitan City by Using SIDRA," in International Conference on Planning, Architecture and Civil Engineering, Rajshahi, Bangladesh, Feb. 2017, Art. no. 6.

[23] HCM, Highway Capacity Manual 2010. Washington, DC, USA: Transportation Research Board, 2010.

[24] Traffic Modelling Guidelines: SIDRA Intersection. Adelaide, SA, Australia: Department for Infrastructure and Transport, 2021.

[25] X. Chen, D. Li, N. Ma, and C. Shao, "Prediction of User Perceptions of Signalized Intersection Level of Service Based on Fuzzy Neural
Networks," Transportation Research Record, vol. 2130, no. 1, pp. 7-15, Jan. 2009, https://doi.org/10.3141/2130-02 . 